\title{
Use of transcatheter valve should not be rationed
}

\author{
Grayson H. Wheatley III, MD
}

The emergence of new technologies for the treatment of aortic valve disorders has brought with it a host of medical and ethical challenges regarding patient selection and choice of treatment. Because of the uncertainty around the safety of new transcatheter aortic valve implantation (TAVI) technologies, early device trials have focused on enrolling and treating patients at high surgical risk who are "non-operative" candidates. Although outcomes for open surgical repair of critical aortic stenosis are improving, early results with TAVI are encouraging and have led to expanded patient selection criteria. ${ }^{1-4}$ Although some clinicians believe that the use of TAVI should be rationed in these non-operative patients, there is a strong argument to make that these patients ethically deserve the same treatment options (when medically appropriate) as younger, less high-risk patients.

\section{ETHICAL AND TREATMENT DECISIONS}

Our hypothetical 75-year-old patient with critical aortic stenosis, multiple comorbidities, and a prior coronary artery revascularization with patent bypass grafts has been determined by the surgical team to be a non-operative candidate, and this patient's situation is becoming increasingly common. Recent data have shown that there are a growing number of similar patients who are denied surgical therapy because of comorbidities. Iung and colleagues ${ }^{5}$ retrospectively showed that $33 \%$ of patients referred for aortic valve replacement were denied surgical repair because of their high surgical risk. The benefits of aortic valve treatment with relief of physiologic gradient across the stenotic aortic valve drastically alters the survival curve of patients compared with medical management. ${ }^{6}$ However, in patients with end-stage disease, TAVI has shown promise of extending life an average of 6 months. $^{7-9}$ The fundamental question becomes, should we? Or in other terms, should we ration health care to patients?

There are 3 different ethical frameworks for which to consider this case: need principles, maximizing principles, and egalitarian principles. ${ }^{10}$ The need principle is based on "rules of rescue," in which the immediate and

From the Department of Cardiovascular Surgery, Arizona Heart Institute, Phoenix, Ariz.

Read at the 91st Annual Meeting of The American Association for Thoracic Surgery, Philadelphia, Pennsylvania, May 7-11, 2011.

Received for publication Feb 3, 2012; accepted for publication Feb 5, 2012

Address for reprints: Grayson H. Wheatley III, MD, Arizona Heart Institute, $2632 \mathrm{~N}$ 20th Street, Phoenix, AZ 85006 (E-mail: GWheatley@azheart.com).

J Thorac Cardiovasc Surg 2012;143:774-5

0022-5223/\$36.00

Copyright (C) 2012 by The American Association for Thoracic Surgery doi:10.1016/j.jtcvs.2012.02.002 long-term medical needs of the patient are the highest priority and supersede all other considerations. This is standard operating practice for most physician-patient interactions in today's healthcare environment. This is the perspective that all of our patients expect from us when making difficult and complex decisions. This traditional approach is intended to offer the best possible outcome and intervention for any patient in need. In this case, it would look simply at the patient and the feasibility of implanting a percutaneous aortic valve. If the patient were deemed a suitable candidate, he or she would be offered this intervention. Because the patient is a candidate for TAVI, it should be offered to the patient to improve his or her quality of life and to relieve suffering. A majority of clinicians would follow this principle of justice. The facts that the patient did not have a welldeveloped support structure to assist him or her after the procedure and that the patient's life expectancy is short are not important drivers of this ethical and moral framework. Essentially, rationing of care is not a consideration with the need principle, and the patient should be offered a TAVI procedure.

The second principle of justice in rationing health care is the maximizing principle. This principle seeks to achieve the best possible consequences, both for the patient and for society as a whole. This slightly broader perspective takes into consideration that this patient has limited support at home and after TAVI would most likely not return to being a productive member of society. The total economic burden of the TAVI procedure, hospitalization, and subsequent care facility is a sizable amount and would certainly have an overall impact on total health care costs. It is difficult for patients to actively engage in this broader perspective because it is difficult for them to fully comprehend the consequences of the therapy in relation to their own debilitated state. The intent here is to maximize well-being for the patient. A TAVI procedure in this patient would certainly improve his or her well-being, and therefore TAVI would meet the threshold for rationing in this patient's case using the maximizing principle and should be offered to the patient.

Finally, the egalitarian principle of justice in health care considers inequalities in health care, and every effort should be made to reduce these inequalities. The total cost of the procedure and rehabilitation is sizeable primarily because of the costs of the percutaneous valve technology compared with a standard aortic valve replacement. From this perspective, the total costs used in the last several months of this patient's life might be better served going to a pediatric patient who has a long prosperous life ahead. As a result, the egalitarian principle would most likely support rationing 
care to this patient, and using this moral framework, the physician should make this informed decision without much input from the patient. This is also the hardest decision to make for the physician because the health care system as a whole is being considered and the patient is left out of this decision-making process. The physician standing at the patient's bedside must look at society's costs in light of the total costs for the patient relative to the expected outcome. Although this type of decision process may be best for the health care system in the long run to help decrease health care expenditures, it is a framework with which we as clinicians are not yet comfortable. With the passage of the US health care reform, tough choices are mandatory to help counteract the increasing health care costs, and rationing of health care will most likely be a new part of providing care. ${ }^{11}$ New technologies, such as TAVI, will certainly receive a great deal of push-back to ration.

In terms of the possibility of rationing TAVI procedures, the costs of this procedure need to be compared with other existing technologies and treatments. $\mathrm{Wu}$ and colleagues ${ }^{12,13}$ have looked at the cost-effective ratio (CER) of standard aortic valve replacement and shown that for a 75 -year-old patient the average CER is $\$ 16,500$. This is compared with a CER of $\$ 50,000$ for TAVI procedures. ${ }^{14}$ These costs take into consideration the quality of life, hospital costs, and need for extended care. Although this difference is substantial, a CER between $\$ 20,000$ and $\$ 100,000$ is acceptable to the US health care system. ${ }^{12}$ As a result, TAVI procedures are justifiable from a cost analysis.

TAVI has already proven to be a successful and useful technology for high-risk surgical patients with critical aortic stenosis. The increased procedural and device costs of TAVI compared with a surgical aortic valve prosthesis and replacement surgery put TAVI procedures at risk for future health care rationing as part of health care reform to minimize growing health care costs in the United States. The CER of TAVI procedures is in line with other existing technologies and therefore should not be singled out as an "expensive" new technology. The principles of justice in health care rationing also support continued use of TAVI procedures in high-risk patients. Future new technologies must face continued evaluation and scrutiny, and physicians must be prepared to be involved in some degree of health care rationing in the future.

\section{References}

1. Leon MB, Smith CR, Mack M, et al. Transcatheter aortic-valve implantation for aortic stenosis in patients who cannot undergo surgery. N Engl J Med. 2010;363: 1597-607.

2. Finks JF, Osborne NH, Birkmeyer JD. Trends in hospital volume and operative mortality for high-risk surgery. N Engl J Med. 2011;364:2128-37.

3. Lee R, Li S, Rankin JS, O'Brien SM, et al. Fifteen-year outcome trends for valve surgery in North America. Ann Thorac Surg. 2011;91:677-84.

4. Jahangiri M, Kappetein AP, van Geldorp M, Bogers AJ. The evolution of advanced techniques for the management of symptomatic aortic stenosis in the elderly population: conventional surgical management vs transcatheter valve implantation. J R Coll Physicians Edinb. 2010;40:323-7.

5. Iung B, Cachier A, Baron G, et al. Decision-making in elderly patients with severe aortic stenosis: why are so many denied surgery? Eur Heart J. 2005;26: 2714-20.

6. Brown ML, Schaff HV, Sarano ME, et al. Is the European System for Cardiac Operative Risk Evaluation model valid for estimating the operative risk of patients considered for percutaneous aortic valve replacement? J Thorac Cardiovasc Surg. 2008;136:566-71.

7. Lefèvre T, Kappetein AP, Wolner E, et al. One year follow-up of the multi-centre European PARTNER transcatheter heart valve study. Eur Heart J. 2011;32: 148-57.

8. Rajani R, Buxton W, Haworth P, et al. Prognostic benefit of transcatheter aortic valve implantation compared with medical therapy in patients with inoperable aortic stenosis. Catheter Cardiovasc Interv. 2010;75:1121-6.

9. Webb JG, Altwegg L, Boone RH, et al. Transcatheter aortic valve implantation: impact on clinical and valve-related outcomes. Circulation. 2009;119. 3009-16.

10. Cookson R, Dolan P. Principles of justice in health care rationing. J Med Ethics 2000;26:323-9.

11. Groeneveld PW, Polsky D, Yang F, et al. The impact of new cardiovascular device technology on health care costs. Arch Intern Med. 2011;171:1289-91.

12. Wu Y, Grunkemeier GL, Starr A. The value of aortic valve replacement in elderly patients: an economic analysis. J Thorac Cardiovasc Surg. 2007;133:603-7.

13. Wu Y, Jin R, Gao G, Grunkemeier GL, Starr A. Cost-effectiveness of aortic valve replacement in the elderly: an introductory study. $J$ Thorac Cardiovasc Surg. 2007; 133:608-13.

14. Reynolds MR. Lifetime cost effectiveness of implantation compared with standard care in inoperable patients: results from the PARTNER Trial (Cohort B). Presented at: the American College Cardiology ACC.11/i2 summit; April 2-5, 2011; New Orleans, LA. 